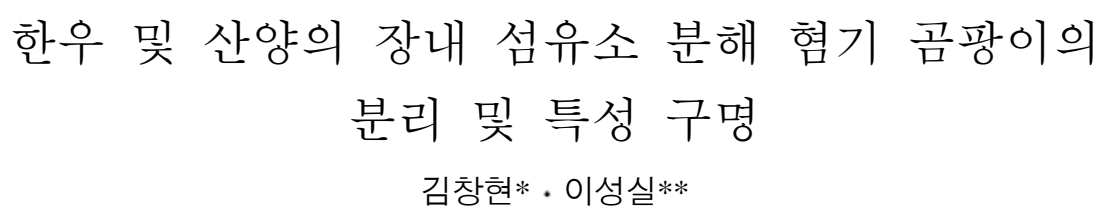

한경대학교 동물생명자원학과*, 경상대학교 동물자원과학부**

\title{
Isolation and Characterization of Cellulolytic Anaerobic Fungi from the Guts of the Hanwoo Cattle and the Korean Native Goat \\ C. -H. Kim* and S. S. Lee**
}

Hankyong National University, Department of Animal Life and Resources*

Gyeongsang National University, Division of Animal Science and Technology**

\begin{abstract}
The study was conducted to isolate and identify highly fibrolytic anaerobic fungi from the guts of a Hanwoo steer and a Korean native goat, and then investigate the characterization of cellulolytic activity of an anaerobic fungus. Twenty-one anaerobic fungal colonies were isolated in the study, in which 16 colonies were isolated from the rumen contents of the Hanwoo steer and 5 colonies from the duodenal fluids of the Korean native goat. Four anaerobic fungi were selected based on higher cellulolytic enzyme activities to identify under a optical microscope. NLRI-M003 and -T004 belong to Neocallimastix genus and NLRI-M014 belongs to Piromyces genus based on the morphology of their thallus, sporangia, rhizoid and the number of flagella. NLRI-M001 appeared to be an unknown strain of anaerobic fungi due to its different morphology from existing types of anaerobic fungi, though the morpholgoy is similar to Orpinomyces sp. Supplementation of $2 \%$ anaerobic fungal culture(NLRI-M003) in rumen-mixed microorganisms increased in vitro DM degradability of rice straw and filter paper up to 4 and $11 \%$, respectively, compared with non-supplementation(control). CMCase and xylanase activities in in vitro culture were also higher in $2 \%$ fungal supplementation than controls in both rice straw and filter paper substrates.
\end{abstract}

(Key words : Anaerobic fungi, Rumen, Duodenum, DM degradability, Cellulolytic activity)

\section{$\mathrm{I}$ 서 론}

반추동물(소와 면양)로부터 혐기 곰팡이가 Orpin(1975)과 Bauchop(1979)에 의해 처음으로 분리되었다. 지금까지 반추동물 및 초식성 비 반추동물로부터 유주자(zoospore)의 모양, 크기 및 편모(flagella)의 수, 엽상체(thallus)의 모양
과 포자낭(sporangia) 수 등에 의해 총 5속(Neocallimastix, Piromyces, Caecomyces, Orpinomyces 및 Ruminomyces 속) 17 종으로 분류되고 있다 (Barr 등, 1989; Breton 등, 1989, 1990, 1991; Lowe 등, 1987a; Orpin, 1975, 1976, 1977).

새로운 종들의 혐기 곰팡이가 반추위 및 다 른 소화기관과 분 등에서 계속적으로 분리될

이 논문은 2000년 한국학술진흥재단 지원(KRF-2000-GA0006) 및 농림기술관리센터(ARPC)의 지원에 의하여 연구되었음.

Corresponding author: Sung S. Lee, Division of Animal Science and Technology, College of Agriculture, Gyeongsang National University, Jinju, 660-701, Korea. Phone : 82-55-751-5411, Fax : 8255-751-5410, E-mail : lss@nongae.gsnu.ac.kr 
것으로 사료되고 있다. 혐기 곰팡이들은 사양 체계 뿐만 아니라 축종과 분리지역에 따라 서 로 다른 분포를 보이며, 같은 종으로 분류된 것이라 할지라도 숙주동물의 종류와 분리부위 에 따라서도 섬유소 분해력에 상당한 차이를 나타낸다고 보고되고 있다(Gordon과 Phillips, 1989a,b; Teunissen 등, 1991; Davies 등, 1993a,b). Theodorou 등(1990) 및 Lowe 등(1987a)은 반 추위내서 발견된 Neocallimastix sp. 그리고 Caecomyces sp.와 형태학적으로 유사한 곰팡이를 분으로부터 분리하였으며, Milne 등(1989)은 약 18 주까지 공기 중에 보관되어 건조된 분으로부 터 생존할 수 있는 혐기 곰팡이를 분리하였다. 특히 Davies 등(1993a)은 소의 십이지장내 혐기 곰팡이가 생존하는 것을 밝혀 산성조건에서도 생존하여 하부 장기에서 출현 할 수 있다고 하 였다.

혐기 곰팡이에 대한 연구의 관심이 집중되고 있는 것은 주로 혐기 곰팡이의 높은 섬유소 분 해력 때문이다. 혐기 곰팡이는 cellulase(Wood 등, 1986)와 xylanase (Mountfort와 Asher, 1989) 를 다량으로 분비하여 반추위내에서 섬유소를 화학적으로 분해시킬 뿐만 아니라 곰팡이의 가 근(rhizoid)은 사료 입자를 붕괴시키거나 굵은 섬유질을 더욱 가늘게 분리시키는 물리적 작용 을 함으로써(Akin과 Benner, 1988; Akin 등, 1989) 세포벽 구성물질을 효과적으로 분해 시 킨다. 또한 반추위 곰팡이의 섬유소 분해 효소 의 활력은 반추위 박테리아 중 섬유소분해 활 력이 가장 높은 Ruminococcus flavefaciences와 Fibrobacter succinogenes보다 3 캐 정도 높게 나타났다(Orpin and Joblin, 1997).

최근에 Lee 등(2000)은 혐기곰팡이의 배양 액을 면양의 반추위에 투여하여 소화율 및 반 추위 발효 개선에 효과가 있다고 하여 혐기 곰 팡이를 이용한 저질조사료 이용성 개선에 대한 관심이 증가되고 있다. 또한 Lee 등(2003)은 Piromyces communis 혐기 곰팡이의 배양액을 혼합 반추위 미생물의 in vitro 배양에 첨가할 경우 섬유소 분해력, 가스 생산성 및 효소의 활력이 증가되었다고 하였다. 그러므로 Berton 등 (1990)이 사하라 사막의 열악한 환경에서 서
식하는 산양(Saharian ass)의 장내로부터 혐기 곰팡이(Piromyces rhizinflata)를 분리한 것과 같 이 열악한 환경조건에 있는 동물의 소화관에서 우수한 섬유소 분해력을 가진 곰팡이의 분리는 우리나라와 같은 저질의 부존조사료원의 이용 성을 개선하는데 많은 영향을 끼치리라 기대된 다. 따라서 본 연구는 저질조사료 공급에도 적 응력이 높은 국내의 재래 반추동물인 재래산양 의 반추위에 서식하는 혐기성 곰팡이와 산성조 건에서 생존 가능한 곰팡이를 분리하기 위해 한우의 십이지장내에 생존 가능한 강력한 섬유 소 분해력을 가진 혐기 곰팡이를 탐색 - 니 및 동정하였다. 또한 선발된 혐기 곰팡이들의 섬유소 분해 특성을 비교하고자 저질 조사료인 볏짚과 filter paper를 기질로 건물분해율과 섬유 소 분해효소의 활력을 측정하였다.

\section{재료 및 방법}

\section{1. 가축 장내 혐기 곰팡이의 분리 및 동정 시험}

(1) 반추위와 십이지장 액으로부터 곰팡이의 분리

십이지장 캐뉼라가 장착된 볏짚과 비육기 배 합사료를 3:7로 급여 받는 한우 1 두로부터 십 이지장액을 채취하였고 볏짚만 급여 받는 반추 위 캐뉼라가 장착된 재래산양 1 두로부터 반추 위액을 채취하였다. 전 시험과정동안 혐기 곰 팡이의 분리 및 계대를 위해서 혐기 가스분주 장치(anaerobic gassing system)를 이용한 Hungate (1966)와 Holdeman(1977)의 방법을 이용하였다. 채취한 소화물들은 섬유소 분해 혐기 곰팡이를 분리하기 위하여 Lowe 등(1985)이 사용한 배지 (medium B; Table 1) 중의 탄수화물원을 분쇄한 (ball-milled) filter paper로 대체하였다. 항생제인 benzyl penicillin, streptomycin sulfate 및 chloramphenicol을 각각 $1.212,0.264$ 및 $0.06 \mathrm{~g} / 100 \mathrm{ml}$ 로 혼합한 복합 항생제를 채취한 소화물에 투 여하여 박테리아의 성장을 억제하였다. 위와 같이 준비된 섬유소 분해 곰팡이 대량배양용 enrichment 배지액속에서 3일간 혐기배양 시켰 
Table 1. Composition of medium B and glucose sloppy medium (GSM) for fungal culture (per 100ml)

\begin{tabular}{|c|c|c|}
\hline Component & medium B & GSM \\
\hline Trypticase peptone, g & 0.10 & 0.10 \\
\hline Yeast extracts, g & 0.05 & 0.10 \\
\hline Glucose, g & 0.25 & 0.15 \\
\hline Cellobiose, g & 0.25 & - \\
\hline Cystein- $\mathrm{HCl} \cdot{ }_{2} \mathrm{O}, \mathrm{g}$ & 0.05 & 0.10 \\
\hline Agar, g & - & 0.10 \\
\hline $\mathrm{NaHCO}_{3}, \mathrm{~g}$ & - & 0.50 \\
\hline Mineral Solution I, ml ${ }^{1)}$ & 7.50 & 16.50 \\
\hline Mineral Solution II, $\mathrm{ml}^{2)}$ & - & 16.50 \\
\hline Macro B solution, $\mathrm{ml}^{3 \text { ) }}$ & 5.40 & - \\
\hline Trace B solution, $\mathrm{ml}^{4)}$ & 1.00 & - \\
\hline VFA mixture solution, $\mathrm{ml}^{5)}$ & 1.00 & - \\
\hline Rumen fluid, ml ${ }^{6)}$ & - & 17.00 \\
\hline $0.1 \%$ Resazurin solution, ml & 0.10 & 1.00 \\
\hline $0.1 \%$ Hemin solution, $\mathrm{ml}$ & 1.00 & - \\
\hline $8 \% \mathrm{NaCO}_{3}$ solution, $\mathrm{ml}$ & 15.00 & - \\
\hline Vitamin mixture solution ${ }^{7)}$ & 1.00 & - \\
\hline Distilled water, ml & 78.00 & 50.00 \\
\hline
\end{tabular}

${ }^{1)} \mathrm{KH}_{2} \mathrm{PO}_{4}, 6.0 \mathrm{~g}$ in $1,000 \mathrm{ml}$ distilled water(DW).

2) $\mathrm{NaCl}, 12.0$ g; $\left(\mathrm{NH}_{4}\right)_{2} \mathrm{SO}_{4} .12 .0 \mathrm{~g} ; \mathrm{KH}_{2} \mathrm{PO}_{4}, 6.0 \mathrm{~g}$; $\mathrm{CaCl}_{2}, 1.2 \mathrm{~g}$; and $\mathrm{MgSO}_{4} \cdot \mathrm{H}_{2} \mathrm{O}, 2.5 \mathrm{~g}$ in $1,000 \mathrm{ml}$ DW.

3) $\mathrm{KCl}, 9.0$ g; $\mathrm{NaCl}, 9.0$ g; $\mathrm{MgSO}_{4} \cdot \mathrm{H}_{2} \mathrm{O}, 7.5$ g; $\mathrm{CaCl}_{2}, 3.0 \mathrm{~g}$; and $\mathrm{NH}_{4} \mathrm{Cl}$, $8.1 \mathrm{~g}$ in $1,000 \mathrm{ml} \mathrm{DW}$.

4) $\mathrm{MnCl}_{2} \cdot{ }_{2} \mathrm{O}, 0.25 \mathrm{~g} ; \mathrm{NiCl}_{2}$. $\mathrm{H}_{2} \mathrm{O}, 0.25 \mathrm{~g} ; \mathrm{NaMoO}_{2}$. $2 \mathrm{H}_{2} \mathrm{O}, 0.25 \mathrm{~g} ; \mathrm{H}_{3} \mathrm{BO}_{3}, 0.25 \mathrm{~g} ; \mathrm{FeSO}_{4} \cdot \mathrm{H}_{2} \mathrm{O}, 0.2 \mathrm{~g}$; $\mathrm{CoCl}_{2} \cdot \mathrm{H}_{2} \mathrm{O}, 0.05$ g; $\mathrm{NaSeO}_{3}, 0.07$ g; $\mathrm{ZnSO}_{4}$. $7 \mathrm{H}_{2} \mathrm{O}, 0.05 \mathrm{~g} ; \mathrm{CuCl}_{2} \cdot \mathrm{H}_{2} \mathrm{O}, 0.025 \mathrm{~g}$; and $\mathrm{NaNO}_{3}$. $4 \mathrm{H}_{2} \mathrm{O}, 0.05 \mathrm{~g}$ in $1,000 \mathrm{ml} 0.2 \mathrm{M} \mathrm{HCl}$ solution.

5) Acetate, $6.85 \mathrm{ml}$; propionate, $3.0 \mathrm{ml}$; butyrate, 1.84 $\mathrm{ml}$; isovalerate, $0.05 \mathrm{ml}$; isobutyrate, $0.47 \mathrm{ml}$; DL-amethylbutyrate, $0.05 \mathrm{ml}$; and n-valerate, $0.55 \mathrm{ml}$ in $700 \mathrm{ml}$ of $0.2 \mathrm{M} \mathrm{NaOH}$; adjust to $\mathrm{pH} 7.5$ wtih $1 \mathrm{M}$ $\mathrm{NaOH}$ then make to $1,000 \mathrm{ml}$ with DW.

${ }^{6)}$ Rumen fluid was obtained by filtering rumen contents, obtained from cattle on rice straw-concentrate ration, through two layers of gauze to remove the large particles and is stored under carbon dioxide in plastic bottles in the refrigerator at $-20^{\circ} \mathrm{C}$ It was melted and centrifuged at $25,000 \times \mathrm{g}$ for $10 \mathrm{~min}$ just before media were prepared.

7) 1.4-naphthoquinone, $0.25 \mathrm{~g}$; calcium D-pantothenate, $0.2 \mathrm{~g}$; nicotinamide, $0.2 \mathrm{~g}$; riboflavin, $0.2 \mathrm{~g}$; thiamin $\mathrm{HCl}, 0.2 \mathrm{~g}$; pyridoxine $\cdot \mathrm{Cl}, 0.2 \mathrm{~g}$; biotin, $0.025 \mathrm{~g}$; folic acid, $0.025 \mathrm{~g}$; cyanocobalamin, 0.025 ; and p-aminobenzoic acid, $0.025 \mathrm{~g}$ in $1,000 \mathrm{ml} 5 \mathrm{mM}$ HEPES buffer solution.
다. 혐기 곰팡이만 대량으로 배양된 배양액을 혐 기 희석액(Bryant와 Burkey, 1953)에서 $\left.10^{-1} \sim\right)^{-9}$ 까지 희석하여 순수분리를 위한 접종액으로 이 용하였다. 섬유소 분해 곰팡이의 분리는 rolltube법을 이용하여 희석된 접종액 $1 \mathrm{ml}$ 을 $2 \%$ agar가 함유된 $9 \mathrm{ml}$ 의 medium $\mathrm{B}$ 에 접종한 후, 시험관을 얼음물 위에서 회전시켜 agar를 굳혔 다. 곰팡이가 접종된 agar 배지를 $39^{\circ} \mathrm{C}$ 서 5 14 일간 배양하며 형성된 colony의 색상, 형태와 크기, 표면의 상태 및 기균사의 발달정도 등을 기준으로 혐기상태 하에서 분리하였다.

분리된 곰팡이들 중에서 섬유소 분해 곰팡이 를 선발하기 위하여 medium B 중에 탄수화물 원을 filter paper strip(Whatman No.1, $20 \times 10 \mathrm{~mm}$ ) 으로 대체하여 배양하였다. 배양 tube 중 배양 액에 탁도(turbidity)가 나타나는 것은 박테리아 가 오염된 것으로 간주하였으며(Joblin, 1981) 탁도가 나타나지 않는 배양 tube의 배양액만 사용하였다. 순수성을 확보하기 위해 복합 항 생제를 사용하여 위와 같은 과정을 반복하며 곰팡이를 순수 분리하였다(이 등, 1995).

(2) 분리된 곰팡이의 섬유소 분해효소 활력 측정

분리된 균주들의 섬유소 분해력을 신속. ! 편하게 비교하기 위하여 섬유소 분해효소인 $\beta$ D-endoglucanase(CMCase, carboxymethylcellulase) 의 활력을 측정하였다. 본 시험에서 분리된 곰 팡이들을 medium $\mathrm{B}$ 에서 3 일 동안 배양한 후 각 균주들의 배양액으로부터 상층액을 채취하 여 $3,000 \mathrm{rpm}$ 에서 20 분 동안 원심분리한 다음 조효소액으로 사용하였다. CMCase의 활력측정 은 조효소액 $0.5 \mathrm{ml}$ 를 각각 취한 후 $0.05 \mathrm{M}$ citrate buffer(pH 5.5)로 부유시킨 $1 \%$ carboxymethylcellulose (w/v; CMC, Sigma C4888)를 $0.5 \mathrm{ml}$ 넣고 $50^{\circ} \mathrm{C}$ 서 1시간 반응시킨 후 $\mathrm{CMC}$ 로부터 유리된 환원당의 양을 dinitrosalicylic acid(DNS, Sigma D0550)을 이용하여 비색법으 로 측정하였다(Miller 등, 1960). 효소의 $1 \mathrm{IU}$ (international unit)은 1 분당 생성된 $1 \mu \mathrm{mol}$ 의 glucose의 양으로 cellulase의 활력을 표시하였다. 
(3) 선발된 섬유소 분해 혐기 곰팡이의 동정 선발된 곰팡이를 동정하기 위하여 광학현미 경(Nikon, Japan)하에서 형태를 관찰하여 Barr (1980)의 방법에 따라 동정을 실시하였다. 광학 현미경 관찰을 위하여 medium $\mathrm{B}$ 에 filter paper $\operatorname{disc}($ Whatman No.1)를 첨가하고 공시균주를 $1 \mathrm{ml}$ 씩 각각 혐기적으로 접종한 다음, 72 시간 동안 $39^{\circ} \mathrm{C}$ incubator에서 배양하였다. 배양이 완료 된 시료는 $400 \sim 1,000$ 배율로 곰팡이와 유주자 를 관찰하였다. 광학현미경 관찰을 위하여 액 체배양액 내에서 곰팡이 colony의 형성과 유주 자의 이동을 제한하기 위하여 Ho 등(1993a,b)이 이용한 glucose sloppy agar medium (Table 1)을 사용하였다.

\section{2. 혐기 곰팡이 배양액의 첨가에 의한 혼합 반추위 미생물의 in vitro 건물 분해율}

앞에서 분리된 혐기 곰팡이 배양액의 첨가가 혼합 반추미생물의 섬유소 분해에 미치는 영향 을 조사하기 위하여 filter paper와 볏짚의 in vitro 건물 분해율과 섬유소 분해효소의 활력을 측정하였다.

\section{(1) 공시 균주 및 첨가수준}

본 실험에서는 앞 실험에서 직접 분리 - 정 된 혐기 곰팡이 중 섬유소 분해율이 가장 높고 대량 배양이 용이한 산양의 반추위로부터 분리 된 혐기 곰팡이 NLRI-M003을 첨가용 균주로 사용하였다. 첨가용 곰팡이 배양액은 medium B 에서 3일 동안 배양된 것을 이용하였다. $50 \mathrm{ml}$ 의 분해율 측정용 배지에 곰팡이 배양액을 $2 \%$ 수준으로 첨가하였다. 섬유소 분해율과 효소활 력을 측정하기 위하여 $2 \mathrm{~mm}$ screen size의 Wiley mill로 분쇄한 볏짚과 Whatman No. 1 filter paper 를 $0.5 \mathrm{~g}$ 씩 각 배지에 첨가하였다. 건물 분해율 을 측정하기 위하여 곰팡이 배양액을 첨가하지 않은 대조구 즉 무첨가구와 첨가구로 나누어 각 기질에 대하여 각각 따로 in vitro 실험을 수 행하였다.

(2) 혼합 반추위 미생물 접종액의 준비 및 접종

볏짚과 농후사료를 7:3으로 급여 받은 반추
위 캐뉼라가 장착된 거세 한우 1 두로 부터 사 료급여 3 시간 후에 $500 \mathrm{ml}$ 의 위액과 $500 \mathrm{~g}$ 의 반 추위 고형물을 채취하였다. 채취한 위액 및 고 형물을 4겹의 가제로 거른 후 $\mathrm{O}_{2}$-free- $\mathrm{CO}_{2}$ 가스 가 충진된 보온병에 넣어 실험실로 운반하였 다. 혐기상태에서 30 분간 $39^{\circ} \mathrm{C}$ - 유지하며 위 액을 정치시킨 후 위액의 상층에 부유하는 사 료입자를 진공펌프를 이용하여 제거한 후 남아 있는 잔류 위액을 혼합 반추위 미생물 접종액 으로 이용하였다. 접종은 $100 \mathrm{ml}$ serum bottle에 각각 $10 \mathrm{ml}$ 의 위액을 접종하고 첨가구에는 $2 \%$ 의 곰팡이 배양액을 첨가하고 무첨가구에는 동 등량의 medium $\mathrm{B}$ 배지를 첨가한 후 buttly rubber stopper와 aluminium seal cap을 이용하여 밀봉하여 bottle내 혐기가 유지되도록 하였다.

(3) 배양시간

혐기 곰팡이 배양액의 첨가에 의한 in vitro 건물 분해율 측정을 위하여 혼합 반추위 미생 물의 배양시간을 균주를 접종한 후 $0,6,12$, $24,48,72$ 및 96 시간 동안 $39^{\circ} \mathrm{C}$ 항온기에서 교 반 없이 배양하였으며, 3반복으로 실험을 수행 하였다. 각 배양시간대별로 볏짚과 filter paper 의 건물분해율과 섬유소 분해효소인 CMCase와 xylanase의 효소활력을 측정하였다.

\section{(4) 건물 분해율의 측정}

배양이 완료된 bottle을 개봉하여 원심분리 (3000 rpm, 20분) 한 후 상층액 $3 \mathrm{ml}$ 을 회수하여 효소 분석용 시료로 보관한 다음 건물 분해율 을 측정하였다. Buchner 깔때기와 Whatman filter paper No. 54 및 진공장치를 이용하여 시 료의 잔량을 측정하여 투입시료량과의 차이를 구하고, 이 차이량을 투입시료량에 대한 백분 율로 환산하여 건물 분해율을 구하였다.

\section{(5) 섬유소 분해효소의 활력}

CMCase의 활력은 전과 동일한 방법으로 측 정하였으며, xylanase의 활력은 $0.5 \mathrm{M}$ potassium phosphate buffer(pH 6.5)의 $2 \%$ oat spelt xylan (w/v; Sigma X0627) 1ml을 이용하여 CMCase 활력분석법과 동일한 방법으로 분석하였다. 


\section{3. 통계분석}

In vitro 건물 분해율 및 효소활력에 대한 무 첨가구와 첨가구간의 결과분석은 SAS package program(1996)을 이용하여 분산분석을 실시하 였다.

\section{III 결과 및 고찰}

1. 한우의 십이지장 및 재래산양의 반추위로 부터 곰팡이의 분리

혐기 생태계로부터 섬유소 분해력이 우수한
곰팡이들을 분리하기 위해서 한우의 십이지장 그리고 볏짚만을 급여한 재래산양의 반추위 내 용물을 수거하여 총 21종의 혐기 곰팡이를 분 리하였다. 산양의 반추위로부터 16종(NLRI-M001 M0016)과 한우의 십이지장 소화물로부터 5종 (NLRI-T001 T005)의 혐기 곰팡이를 분리하였 다. 곰팡이의 분리하는 과정 중에서 나타난 colony의 특성과 성장 특성은 Table 2에 나타내 었다.

7일 동안 성장시킨 colony의 색은 주로 흰색, 노란색 및 황색이었는데 colony의 중앙에는 진 한 황색, 가운데 부분은 노란색 그리고 가장자

Table 2. Growth characteristics, and the color, type and size of fungal colony isolated from the duodenum of a Hanwoo steer and the rumen of a Korean native goat

\begin{tabular}{|c|c|c|c|c|c|}
\hline \multirow{3}{*}{ Isolates $^{1)}$} & \multicolumn{4}{|c|}{ Colony } & \multirow{3}{*}{ Aerobic growth } \\
\hline & \multicolumn{2}{|c|}{ Color ${ }^{2)}$} & \multirow{2}{*}{ Туре } & \multirow{2}{*}{$\operatorname{Size}^{3)}(\mathrm{mm})$} & \\
\hline & I & $\mathrm{E}$ & & & \\
\hline NLRI-M001 & $\mathrm{W}^{4)}$ & $\mathrm{W}$ & Circular & 70 & - \\
\hline NLRI-M002 & $\mathrm{W}$ & W & Circular & 30 & - \\
\hline NLRI-M003 & $\mathrm{W}$ & W & Irregular & 40 & - \\
\hline NLRI-M004 & W & W & Circular & 20 & - \\
\hline NLRI-M005 & - & W & Irregular & 170 & - \\
\hline NLRI-M006 & $\mathrm{Y}$ & W & Oval & 50 & - \\
\hline NLRI-M007 & $\mathrm{W}$ & W & Irregular & 20 & - \\
\hline NLRI-M008 & $\mathrm{Y}$ & W & Oval & 60 & - \\
\hline NLRI-M009 & W & W & Irregular & 40 & - \\
\hline NLRI-M010 & $\mathrm{Y}$ & W & Circular & 60 & - \\
\hline NLRI-M011 & $\mathrm{Y}$ & W & Circular & 20 & - \\
\hline NLRI-M012 & $\mathrm{Y}$ & W & Irregular & 30 & - \\
\hline NLRI-M013 & $\mathrm{W}$ & W & Irregular & 20 & - \\
\hline NLRI-M014 & $\mathrm{Y}$ & W & Oval & 40 & - \\
\hline NLRI-M015 & $\mathrm{Y}$ & W & Irregular & 30 & - \\
\hline NLRI-M016 & - & W & Oval & 210 & - \\
\hline NLRI-T001 & $\mathrm{W}$ & W & Circular & 25 & - \\
\hline NLRI-T002 & W & W & Circular & 90 & - \\
\hline NLRI-T003 & $\mathrm{W}$ & W & Irregular & 35 & - \\
\hline NLRI-T004 & $\mathrm{Y}$ & $\mathrm{Y}$ & Irregular & 20 & - \\
\hline NLRI-T005 & $\mathrm{Y}$ & W & Circular & 20 & - \\
\hline
\end{tabular}

${ }^{1)}$ NLRI-M : Fungi isolated from the goat, NLRI-T : Fungi isolated from the Hanwoo steer.

${ }^{2)}$ I : Internal parts of colony, E : External parts of colony.

3) Measured in diameter.

4) $\mathrm{Y}$ : Yellow, W : White. 
리로 갈수록 옅어지는 colony와 colony 전체가 흰색인 것이 가장 많았다. 그러나 성장시기에 따라 colony의 색은 많은 변화를 일으켜 초기 에는 흰색의 점으로 성장을 시작하여 3 4일경 부터 중앙부분이 황색으로 변하며 5 6일 이후 부터는 급속히 성장하여 가장자리에 흰색의 환 을 형성하기 시작하는데 이는 곰팡이의 가근의 성장에 따른 영향인 것으로 생각되었다. 혐기 곰팡이 colony의 형태는 circular 형태에서 irregular 형태에 이르기까지 다양하였으나 둥근 것 이 많았으며 또한 형태는 둥글지만 가장자리가 불규칙하게 성장한 형태 또한 많았다. Colony의 크기는 직경이 $210 \mathrm{~mm}$ 인 것부터 $20 \mathrm{~mm}$ 까지 다양 하였으며 대부분이 $20 \sim 60 \mathrm{~mm}$ 범위의 크기를 가졌다. 이 등(1995)은 배양 $7 \sim 8$ 일 후 물리적 변화 폭이 두드러지게 나타나지 않아 성장이 완 료되었을 때 대부분의 colony가 중앙부위가 황 색이고 가장자리가 흰색인 $10 \sim 20 \mathrm{~mm}$ 의 크기 를 갖는다고 하였다. 본 연구의 결과는 이 등 (1995)이 관찰한 혐기 곰팡이의 colony 크기보다 월등히 컸으며 이러한 차이는 비록 이용된 배지 가 같은 medium $\mathrm{B}$ 일 지라도 배양조건의 차이와 분리된 동물의 종류, 소화장기의 종류 또는 지 역적 분포 등에 따라서 곰팡이의 종류나 곰팡이 의 활성이 서로 다를 수 있기 때문인 것으로 사 료된다. 본 시험에서 분리한 곰팡이들 중에서는 호기상태에서 성장하는 균주가 하나도 발견되지 않았다. 이러한 것은 반추위 곰팡이는 $\mathrm{O}_{2}$ 의 함 량이 반추위내 $0.3 \%$ 미만에서 성장하는 편성 혐 기성이기기 때문인(Orpin, 1975; Lowe 등, 1985, 1987a,b) 것으로 사료된다.

Roll tube상에서 분리된 혐기 곰팡이들의 섬 유소 분해력을 신속 - ㄴ편하게 screening하기 위 하여 carboxymethyl cellulose를 기질로 하여 각 곰팡이 배양액의 상층액과 반응시켜 CMCase의 효소활력 test를 수행하여 측정한 결과는 Table 3 에서와 같다.

21종 중 재래산양으로부터 분리된 곰팡이중 10 종과 한우로부터 분리한 곰팡이 중 3 종은 CMCase에 대한 활력이 아주 미약하거나 활력 을 보이지 않았다. 전반적인 섬유소 분해효소의
활력은 약 $30 \mu \mathrm{mol} / \mathrm{min} / \mathrm{ml}$ 정도 이었으며 그

Table 3. Extracellular cellulase activity(CMCase; $\mu \mathrm{mol} / \mathrm{min} / \mathrm{ml}$ ) of fungi isolated from a Hanwoo steer and a Korean native goat

\begin{tabular}{|c|c|}
\hline \multicolumn{2}{|c|}{ Fungi isolated from the goat } \\
\hline Strains & CMCase activity \\
\hline NLRI-M001 & 32.66 \\
\hline NLRI-M002 & 17.31 \\
\hline NLRI-M003 & 75.59 \\
\hline NLRI-M004 & 28.98 \\
\hline NLRI-M010 & 32.19 \\
\hline NLRI-M014 & 34.76 \\
\hline \multicolumn{2}{|c|}{ Fungi isolated from the Hanwoo } \\
\hline Strains & CMCase activity \\
\hline NLRI-T001 & 30.74 \\
\hline NLRI-T003 & 28.01 \\
\hline NLRI-T004 & 32.67 \\
\hline
\end{tabular}

중 한우로부터 분리된 혐기 곰팡이 NLRI-M003 이 CMCase activity가 $75.59 \mu \mathrm{mol} / \mathrm{min} / \mathrm{ml}$ 로 가장 높게 나타났다.

2. 한우의 십이지장 및 재래산양의 반추위로 부터 분리된 곰팡이의 동정

총 21종의 순수 분리된 혐기 곰팡이들에 대 한 섬유소 분해 효소(CMCase)의 활력을 측정하 여 그 중 섬유소 분해력이 우수한 4종을 최종 선발하였다. 선발된 4종의 혐기성 곰팡이에 대 하여 광학현미경 하에서 형태특성을 관찰하여 동정 작업을 수행하였다. 이들 4종의 곰팡이의 미세구조에 대한 광학현미경을 통하여 관찰한 모습은 Fig. 1, 2, 3 및 4에서와 같으며 Table 4 에서 이들의 형태와 유주자의 형태 등을 종합 하여 동정한 결과를 나타내었다.

반추위 곰팡이의 성장형태는 monocentric 형 태가 3종(NLRI-M003, -M014 및 -T004)이었고, NLRI-M001 1종만이 polycentric형태였다. 특히, NLRI-M001은 포자낭이 다양하게 분화된 형태 로 지금까지 밝혀진 혐기 곰팡이와는 다른 특이 한 모습을 보였다. 현재까지 밝혀진 혐기 반추 위 곰팡이 5속 중에서 Neocallimastix, Piromyces 및 Ceacomyces는 monocentric, 나머지 Orpino- 
myces와 Ruminomyces는 polycentric의 성장형태를 NLRI-M001은 Orpinomyces 또는 Ruminomyces 에 속하는 곰팡이로 생각되었다.

Table 4. Identification and morphological characteristics of anaerobic fungal strains isolated from a Hanwoo steer and a Korean native goat

\begin{tabular}{|c|c|c|c|c|c|c|}
\hline \multirow{2}{*}{ Isolates } & \multirow{2}{*}{$\begin{array}{l}\text { Growth } \\
\text { pattern }\end{array}$} & \multicolumn{2}{|l|}{ Sporangial } & \multirow{2}{*}{$\begin{array}{c}\text { Zoospore filagella } \\
\text { type }\end{array}$} & \multirow{2}{*}{$\begin{array}{l}\text { Rhizoidal } \\
\text { patterns }\end{array}$} & \multirow{2}{*}{$\begin{array}{c}\text { Identification of } \\
\text { Genus }\end{array}$} \\
\hline & & Morphology & Stalk & & & \\
\hline NLRI-M001 & Poly & Variable fusiform & + & Multi & Filament & Unknown \\
\hline NLRI-M003 & Mono & Globose & $+/-$ & Multi & Filament & Neocallimastix \\
\hline NLRI-M014 & Mono & Fusiform & + & Uni & Filament & Piromyces \\
\hline NLRI-T004 & Mono & Oval & + & Multi & Filament & Neocallimastix \\
\hline
\end{tabular}

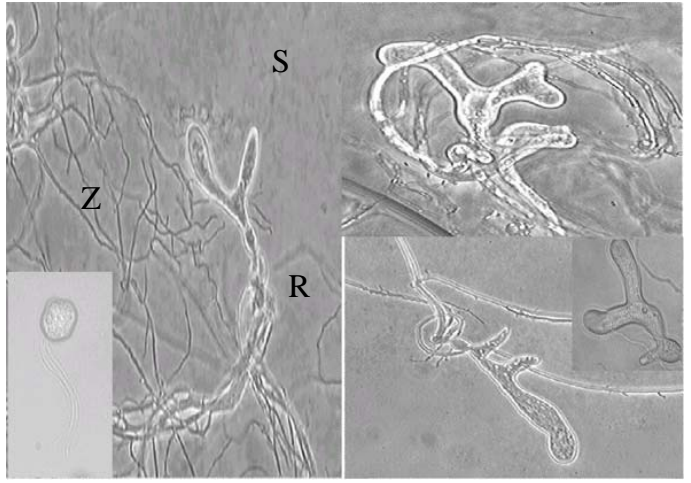

Fig. 1. Optical micrographs of the morphology of an anaerobic fungus, NLRI-M001 after $72 \mathrm{hr}$ of incubation at $39^{\circ} \mathrm{C}$, sporangia; Z, zoospore; R, rhizoid). $\mathrm{S}$

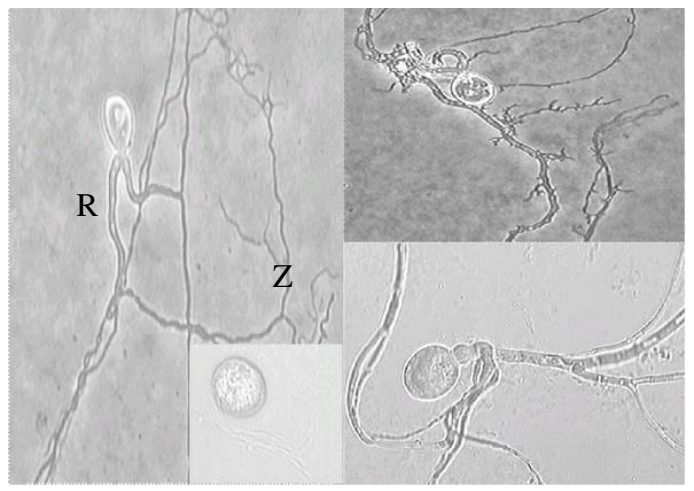

Fig. 2. Optical micrographs of the morphology of an anaerobic fungus, NLRI-M003 after $72 \mathrm{hr}$ of incubation at $39^{\circ} \mathrm{C}$;, sporangia; Z, zoospore; R, rhizoid).

취하고 있다(Gaillard-Martinie 등, 1992). 그러므 로 앞의 3종의 혐기 곰팡이는 Neocallimastix, Piromyces 또는 Ceacomyces 속의 곰팡이이며
분리된 곰팡이 4종의 포자낭 형태는 분리번호 NLRI-M001이 끝이 두 개 이상의 갈라진 방추형 (fusiform), NLRI-M003은 구형(globose), NLRIM014는 난형에 가까운 구형(oval, globose and variable) 및 NLRI-T004는 난형(Oval)으로 나타났 다. 가근의 형태를 비교하였을 때 NLRI-M001은 얇은 수많은 가근을 가지고 있으며 NLRI-M003 과 -M004은 굵은 몇 개의 가근으로부터 많은 수의 가근들이 세분되어 있었다. 또한 NLRIT004는 두 개의 굵은 가근이 나선형을 이룬 후 다수의 가근으로 세분이 되었다. 지금까지 밝 혀진 혐기 곰팡이의 포자낭 형태는 구형, 난형, 구형+난형의 복합형, 방추형 및 끝이 갈라진 방추형의 다섯 가지가 보고되고 있다. 구형의 포자낭 형태를 가진 혐기 곰팡이에는 N. joyonii (Breton et al., 1989), P. dumbonicus(Li et al., 1990), P. spiralis(Ho et al., 1993a), C. communis (Gold et al., 1988) 및 O. bovis(Barr et al., 1989) 등이 알려져 있다. 난형의 포자낭을 가진 혐기 곰팡이에는 $N$. frontalis(Heath et al., 1983)와 $N$. patriciarum(Orpin and Munn, 1986)이 알려져 있다. 구형 및 난형의 복합형을 가진 혐기 곰팡이는 P. communis(Gold et al, 1988), $N$. hurleyensis(Webb et al., 1988) 및 $N$. variabilis (Ho et al., 1993b) 등이 알려져 있다. 방추형 및 끝이 갈라진 방추형의 포자낭을 가지고 있는 혐기 곰팡이로는 P. mae(Gaillard-Martinie et al., 1992)와 R. elegans(Ho et al., 1990) 등이 알려져 있다. 혐기 곰팡이의 가근은 filamentous 형태와 bulbous형태 2가지로 구분되는데 Caecomyces sp.를 제외한 다른 혐기 곰팡이는 filamentous 형태의 가근을 가지고 있다. 본 연구에서 분리 
된 곰팡이의 rhizoid는 모두가 filament 형태로 나타났다.

유주자의 미세구조 즉, flagella의 수와 크기 는 종을 동정하는 필수적인 요소로서 Piromyces, Caecomyces 및 Ruminomyces 속은 단지 한 개의 flagellum이 붙어 있는 형태를 취하고 나머지 속들은 유주자에 여러 개의 flagella가 붙어 있 는 형태를 취하며 그 길이는 종을 구명하는 단 서로 이용되지만 본 연구에서는 flagella의 길이 는 측정되지 않았고 복수 flagella 인지 단수의 flagellum 인지 만 구분되었다. 본 시험에서 분 리된 곰팡이 중 3종(NLRI-M001, NLRI-M003 및 NLRI-T004)의 유주자는 모두 구형의 형태로 복수의 flagella 형태였으며, NLRI-M014만이 구 형이며 단수의 flagellum 형태였다. 유주자의 flagella 수는 Neocallimastix sp.과 Orpinomyces sp. 이 다수의 편모를 가지고 있다. N. patriciarum 은 약 9 7개, $N$. frontalis는 7 )개의 flagella 가 있으며(Heath 등, 1983; Webb와 Theodorou 등, 1988), N. joyonii는 12 j개(Breton 등, 1989; Webb와 Theodorou 등, 1988), O. bovis는 10 j개의 flagella를 가지고 있다. 그러나 Fig. $1,2,3$ 및 4의 사진을 보듯이 유주자의 flagella 수를 측정하는 것은 상당한 어려움이 있고 앞의 연구자들 또한 같은 종의 곰팡이일지라도 flagella의 수가 항상 일치하지 않고 변이가 있음 을 보고하고 있어 flagella의 수로 동정을 하는 것은 많은 어려움이 여전히 있다고 사료된다.

광학현미경에 의한 형태학적 관찰을 기초로 4종의 곰팡이를 동정하면(Table 3), NLRI-M003 은 monocentric 성장형태, 구형의 포자낭, filamentous rhizoid 및 유주자의 flagella가 다수인 Neocallimastix sp.로, NLRI-M014는 monocentric 성장형태, 방추형의 포자낭, filamentous rhizoid 및 다수의 flagella를 가진 유주자를 갖는 Piromyces sp.로, NLRI-T004는 monocentric 성장 형태, 난형의 포자낭, filamentous rhizoid 및 유 주자의 flagella가 다수인 Neocallimastix sp.로 각 각 사료된다. 그러나 NLRI-M001은 복수의 포 자낭을 가지고 있는 Orpinomyces sp. 와 유사한 것으로 추측되나 지금까지 밝혀진 곰팡이 이외 에 다른 밝혀지지 않은 곰팡이가 존재할 가능
성이 있을 것으로 평가되어 더욱 더 세부적인 조사가 필요하다고 생각된다.

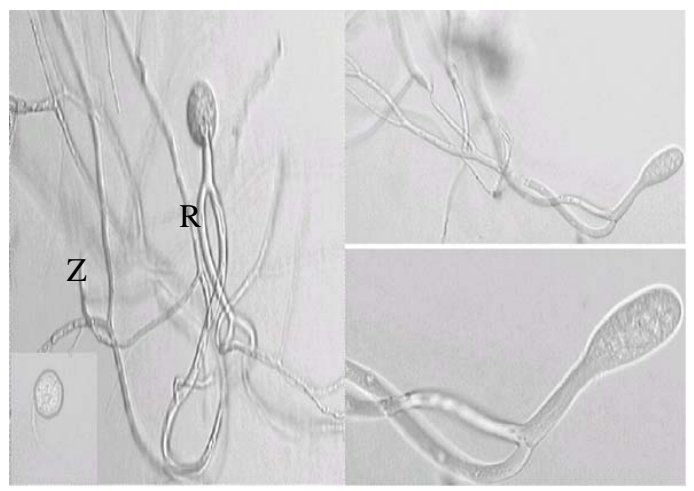

Fig. 3. Optical micrographs of the morphology of an anaerobic fungus, NLRI-M014 after $72 \mathrm{hr}$ of incubation at $39^{\circ} \mathrm{C}(\mathrm{S}$, Zsporangsa; Z, zoospore; R, rhizoid).

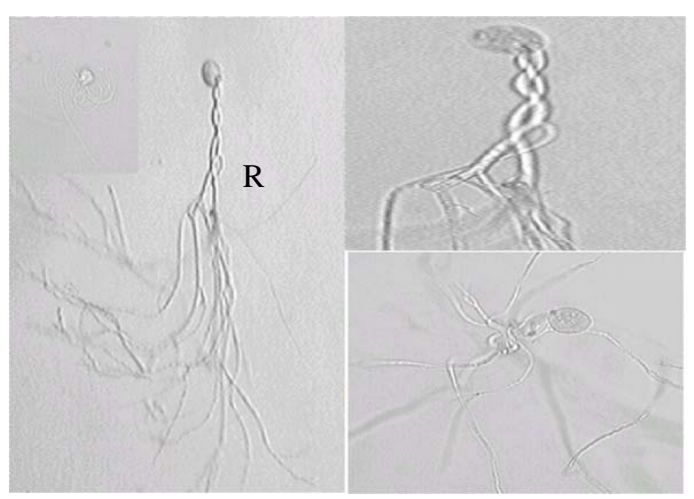

Fig. 4. Optical micrographs of the morphology of an anaerobic fungus, NLRI-T004 after $72 \mathrm{hr}$ of incubation at $39^{\circ} \mathrm{C}$;, sporangia; Z, zoospore; R, rhizoid).

\section{3. 혐기 곰팡이의 첨가에 의한 in vitro 건물 분해율 및 섬유소 분해 효소 활력}

산양의 반추위로부터 분리된 NLRI-M003 혐 기 곰팡이 배양액을 $2 \%$ 첨가시 in vitro 건물 분해율이 볏짚과 filter paper를 기질로 한 모든 처리구에서 24시간 배양 이전까지는 무첨가구 와 첨가구간 차이가 없었지만 48시간 배양 이 후부터 기질들의 건물 분해율이 유의적으로 증 가하였다. 볏짚을 기질로 하였을 때 곰팡이 배 양액 무첨가구와 첨가구의 최종 건물 분해율은 각각 54.4와 58.6\%로 나타났으며 filter paper를 
기질로 하였을 때 건물 분해율은 무첨가구와 첨가구 각각 47.3 및 $58.3 \%$ 로 측정되어 볏짚의 경우 약 $4 \%$ 이상 $(\mathrm{k}<0.05)$ 그리고 filter paper를 기질로 사용 시 $11 \%$ 이상 $(\mathrm{f}<0.001)$ 의 in vitro 건물 분해율 증가를 볼 수 있었다(Fig. 5). 일반 적으로 볏짚과 filter paper간의 혼합 반추위 미 생물에 의한 in vitro 분해율을 보면 filter paper 가 분해율이 높은데 이러한 것은 filter paper가 순수 cellulose로 구성이 되어있고 그 반면 볏짚 은 다양한 구조탄수화물들(lignin, hemicellulose, cellulose 및 pectin 등)과 볏짚의 외피가 silica와 큐틴 등으로 덮여있기 때문에 filter paper에 비 하여 반추위 미생물들이 분해가 용이하지 못하 다. 그러나 본 연구에서는 볏짚을 기질로 하였 을 때 분해율이 filter paper보다 무첨가구에서는 상당히 높았고 첨가구에서는 비슷한 경향이었 는데 이러한 것은 볏짚과 filter paper를 기질로 하여 동일한 시기에 채취한 반추위액으로 in vitro 배양 시험을 하였을 때에는 전자에서 언 급한 것과 같이 filter paper의 분해율이 높을 수 있었을 것이다. 하지만 본 연구에서는 비록 같 은 소의 반추위액으로부터 접종액을 사용하였 지만 각 기질별로 다른 시기에 위액을 채취하 여 시험에 이용하였기 때문에 배양조건 등에 약간의 차이가 있었던 것으로 사료된다. Jones 와 Hayward(1975)도 반추위액을 이용한 in vitro 소화율 시험에서 반추위액에 의해 발생할 수 있는 여러 변이 조건들을 지적한 바 있다.
곰팡이 첨가구에서 분해율의 증가를 뒷받침 해주듯 Table 5와 6에서 CMCase와 xylanase 효

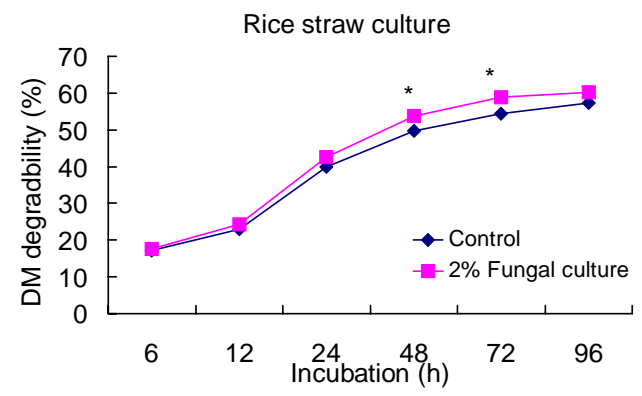

(A)

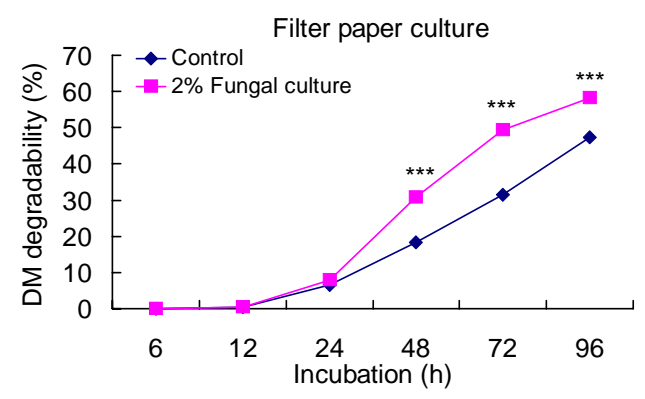

(B)

Fig. 5. Effects of supplementation of $2 \%$ anaerobic fungal culture on in vitro DM degradability (\%) of rumen mixed microorganisms when rice straw (A) and filter paper (B) were used as substrates $(* \star, r<0.01 ; * \star *, r<0.001)$.

소의 활력이 첨가구에서 증가하였으며 특히 반 추위 곰팡이는 강력한 xylanase 효소활력을 보

Table 5. Effects of supplementation of $2 \%$ anaerobic fungal culture (FC) on CMCase activity $(\mu \mathrm{mol} / \mathrm{min} / \mathrm{ml})$ of rumen mixed microorganisms when rice straw and filter paper were used as substrates

\begin{tabular}{|c|c|c|c|c|c|c|}
\hline \multirow{2}{*}{ Treatments } & \multicolumn{6}{|c|}{ Incubation time(hr) } \\
\hline & 6 & 12 & 24 & 48 & 72 & 96 \\
\hline \multicolumn{7}{|l|}{ Rice straw } \\
\hline Control & $3.57 \pm 0.770^{1)}$ & $4.27 \pm 0.833$ & $2.89 \pm 0.888$ & $1.93 \pm 0.465$ & $4.91 \pm 0.530$ & $0.31 \pm 0.001$ \\
\hline FC & $2.80 \pm 0.662$ & $5.21 \pm 1.110$ & $2.89 \pm 0.179$ & $2.13 \pm 0.299$ & $4.44 \pm 0.129$ & $1.75 \pm 0.060$ \\
\hline Significnace & + & + & ns & ns & ns & $*$ \\
\hline \multicolumn{7}{|l|}{ Filter paper } \\
\hline Control & $3.50 \pm 1.032$ & $3.19 \pm 1.106$ & $14.00 \pm 1.830$ & $24.83 \pm 3.481$ & $10.48 \pm 2.130$ & $23.16 \pm 2.910$ \\
\hline FC & $3.71 \pm 0.962$ & $2.81 \pm 0.970$ & $22.35 \pm 9.958$ & $40.57 \pm 5.870$ & $30.07 \pm 4.574$ & $19.41 \pm 2.220$ \\
\hline Significance & ns & ns & ns & $*$ & $* *$ & ns \\
\hline
\end{tabular}

${ }^{1)}$ Mean \pm SEM.

**, I $<0.01 ; *$, I $<0.05 ;+$, I $<0.10$; and ns, not significant. 
여주었다. 혐기 곰팡이는 박테리아와 프로토조 이며 반추 동물의 생산성을 향상시킬 수 있 아와 같이 다당류의 소화에 관련되는 많은 효 으리라 기대된다.

Table 6. Effects of supplementation of $2 \%$ anaerobic fungal culture (FC) on xylanase activity $(\mu \mathrm{mol} / \mathrm{min} / \mathrm{ml})$ of rumen mixed microorganisms when rice straw and filter paper were used as substrates

\begin{tabular}{|c|c|c|c|c|c|c|}
\hline \multirow{2}{*}{ Treatments } & \multicolumn{6}{|c|}{ Incubation time (hr) } \\
\hline & 6 & 12 & 24 & 48 & 72 & 96 \\
\hline \multicolumn{7}{|l|}{ Rice straw } \\
\hline Control & $98.0 \pm 10.20$ & $48.0 \pm 1.17$ & $50.8 \pm 1.57$ & $10.3 \pm 2.16$ & $6.4 \pm 2.41$ & $2.5 \pm 1.28$ \\
\hline FC & $89.8 \pm 2.32$ & $52.23 \pm 2.46$ & $70.1 \pm 4.45$ & $15.2 \pm 0.54$ & $9.7 \pm 0.44$ & $2.0 \pm 0.16$ \\
\hline Significnace & ns & + & $*$ & * & ns & ns \\
\hline \multicolumn{7}{|l|}{ Filter paper } \\
\hline Control & $109.2 \pm 8.22$ & $39.7 \pm 3.72$ & $181.3 \pm 12.31$ & $214.9 \pm 16.27$ & $231.4 \pm 51.31$ & $362.8 \pm 11.69$ \\
\hline FC & $93.8 \pm 2.60$ & $31.69 \pm 2.74$ & $164.4 \pm 10.58$ & $359.8 \pm 39.05$ & $556.3 \pm 1.48$ & $380.3 \pm 17.73$ \\
\hline Significance & ns & ns & ns & * & ** & ns \\
\hline
\end{tabular}

소를 분비한다. 특히, 다른 미생물군에 비하여 혐기 곰팡이는 많은 양의 cellulase(Wood 등, 1986)와 xylanase(Mountfort와 Asher, 1989)를 분 비하며, 이들 효소는 반추위내에서 섬유질 사 료의 분해에 매우 중요한 역할을 하는데, 특히 혐기 곰팡이가 분비하는 효소 중에는 hemicellulose를 분해하는 xylanase가 다량으로 함유 되어 있다는 것이 특징이며, 이 xylanase가 사 료의 섬유성물질을 분해 시키는데 있어서 1 차 적 기능을 담당하게 된다(Williams and Orpin, 1987; Mountfort와 Asher, 1989b).

결론적으로 비록 한우 십이지장에서 분리된 혐기 곰팡이의 섬유소 분해력은 낮은 편이었 지만 Davies 등(1993a)이 언급하였듯이 반추 동물의 십이지장내에 혐기 곰팡이가 분리된 다는 것이 증명되었고 완벽한 동정은 이루어 지지 않았지만 지금까지는 밝혀지지 않은 곰 팡이가 존재할 가능성이 있을 것으로 평가되 었다. 또한 혼합 반추위 미생물의 in vitro 배 양에 혐기 곰팡이 배양액을 첨가하였을 때 섬유소 분해율이 증가되며 이러한 것은 주로 섬유소 분해 효소의 역할이 컸음을 알 수 있 었다. 앞으로 이러한 혐기 곰팡이의 대량 배 양 및 보존 방법을 개발한다면 반추 동물의 발효조건을 개선하고 섬유소 분해력을 증가 시킴으로써 결국 저질조사료의 활용도를 높

\section{IV 요 약}

본 연구는 국내의 재래 반추동물인 재래산양 과 한우의 장내에 서식하며 강력한 섬유소를 분해하는 혐기 곰팡이를 탐색하고 분리하여 섬 유소 분해 특성을 구명하고자 실시되었다. 산 양의 반추위로부터 16 종과 한우의 십이지장 소 화물로부터 5 종의 혐기 곰팡이를 분리하여 총 21종의 혐기성 곰팡이가 분리되었다. 섬유소 분해효소의 활력을 측정하여 그 중 섬유소 분 해력이 높은 4종의 곰팡이에 대하여 광학현미 경에 의한 형태학적 관찰을 기초로 동정 작업 을 수행하였다. NLRI-M003은 monocentric 성장 형태, 구형의 포자낭, filamentous rhizoid 및 유 주자의 flagella가 다수인 Neocallimastix sp., NLRI-M014는 monocentric 성장형태, 방추형의 포자낭, filamentous rhizoid 및 유주자의 flagella 가 단수인 Piromyces sp.로, NLRI-T004는 monocentric 성장형태, 난형의 포자낭, filamentous rhizoid 및 유주자의 fagella 수가 다수인 Neocallimastix sp.로 각각 확인되었다. NLRI-M001은 Orpinomyces sp. 와 유사한 것으로 추측되나 지 금까지 밝혀진 곰팡이 이외에 다른 밝혀지지 않은 곰팡이가 존재할 가능성이 있을 것으로 평가되어 더욱 더 세부적인 조사가 필요하다고 
사료되었다. 혐기 곰팡이의 섬유소 분해 특성 을 조사하기 위해 산양의 반추위로부터 분리된 NLRI-M003 혐기 곰팡이 배양액을 $2 \%$ 첨가하 여 혼합 반추위 미생물의 in vitro 건물 분해율 을 볏짚과 filter paper를 기질로 하여 조사하였 다. 모든 처리구에서 혐기 곰팡이 배양액을 첨 가한 첨가구가 무첨가구에 비하여 볏짚의 경우 약 $4 \%$ 이상 $(\mathrm{r}<0.05)$ 그리고 filtre paper를 기질 로 사용시 $11 \%$ 이상 $(\mathrm{y}<0.001)$ 의 분해율이 증 가하였다. 또한 CMCase와 xylanase 효소의 활 력도 첨가구에서 증가하였으며 특히 반추위 곰 팡이는 강력한 xylanase 효소활력이 높음을 보 여주었다.

(주요어 : 혐기 곰팡이, 반추위, 십이지장, 건물 분해율, 섬유소 분해)

\section{$\mathrm{V}$ 인 용 문 헌}

1. Akin, D. E. and Benner, R. 1988. Degradation of polysaccharides and lignin by ruminal bacteria and fungus. Appl. Environ. Microbiol. 54:1117.

2. Akin, D. E. 1989. Histrological and physical factors affecting digestibility of forages. Agron. J. 81:17.

3. Barr, D. J. S. 1980. An outline for the reclassification of the Chytridiales, and for a new order, the Spizellomycetales. Can. J. Bot. 58:2380.

4. Barr, D. J. S., Kudo, H., Jakober, K. and Cheng, K.-J. 1989. Morphology and development of rumen fungi: Neocallimastix sp, Piromyces communis and Orpinomyces bovis gen. nov., sp. nov. Can. J. Bot. 67:2815.

5. Bauchop, T. 1979. Rumen anaerobic fungi of cattle and sheep. Appl. Environ. Microbiol. 38:148.

6. Breton, A., Dusser, M. and Fonty, G. 1989. Morphological and metabolic characterization of a new species of strictly anaerobic rumen fungus; Neocallimastix jouonii. FEMS Microbiol. Lett. 58:309.

7. Breton, A., Bernalier, A., Dusser, M., Fonty, G., Gaillard-Martinie, B. and Guilot, J. 1990. Anaeromyces mucronatus nov. gen., nov. sp. A new strictly anaerobic rumen fungus with polycentric thallus. FEMS Microbiol. Lett. 70:177.

8. Breton, A., Dusser, M., Gaillare-Martinie, B., Guillot, J., Millet, L. and Prensier, G. 1991. Piromyces rhizinflata nov. sp., A strictly anaerobic fungus from faeces of the Saharan ass: a morphological, metabolic and ultrastructural study. FEMS Microbiol. Lett. 82:1.

9. Bryant, M. P. and Burkey, L. A. 1953. Culture m ethods and some characteristics of some of the more numerous groups of bacteria in the bovine rumen. J. Dairy Sci. 36:205.

10. Davies, D. R., Theodorou, M. K., Lawrence, M. I. and Trinci, A. P. J. 1993a. Distribution of anaerobic fungi in the digestive tract of cattle and their survival in faeces. J. Gen. Microbiol. 139:1395.

11. Davies, D. R., Theodorou, M. K., Brooks, A. E. and Trinci, A. P. J. 1993b. Influence of drying on the survival of anaerobic fungi in rumen digesta and faeces of cattle. FEMS Microbiol. Lett. 106:59.

12. Gaillard-Martinie, B., Breton, A., Martine, D. and Guillot, J. 1992. Contribution to the morphological and ultrastructural characterization of Piromyces mae, a strictly anaerobic rumen fungus. Current Microbiol. 24:159.

13. Gold, J. J., Heath, I. B. and Bauchop, T. 1988. Ultrastructural description of new chytrid genus of caecum anaerobe. Caecomyces equi gen. nov. Biosystmes. 21:403.

14. Gordon, G. L. R. and Phillips, M. W. 1989a. Comparative fermentation properties of anaerobic fungi from the rumen. In "The Roles of Protozoa and Fungi in Ruminant Digestion” Eds by J. V. Nolan, R. A. Leng and D. I. Demeyer, p. 127. Penambul Books, Armidale, Australia.

15. Gordon, G. L. R. and Phillips, M. W. 1989b. Degradation and utilization of cellulose and straw by three different anaerobic fungi from the ovine rumen. Appl. Environ. Microbiol. 55:1703.

16. Heath, I. B., Bauchop, T. and Skipp, R. A. 1983. Assignment of the rumen anaerobe Neocallimastix frontalis to the Spizellomycetales (Chytridiomycetes) on the basis of its polyflagellate zoospore ultrastructure. Can. J. Bot. 61:295.

17. Ho, Y. W., Barr, D. J. S., Abdullah, N., Jalaludin, S. and Kudo, H. 1993a. Priomyces spiralis, A new species of anaerobic fungus from the rumen of goat. Mycotaxon. XLVII:59.

18. Ho, Y. W., Barr, D. J. S., Abdullah, N., Jalaludin, S. and Kudo, H. 1993b. Neocallimastix variabilis, A new species of anaerobic fungus from the rumen of cattle. Mycotaxon. XLVI:241.

19. Ho, Y. W., Bauchop, T., Abdullah, N. and Jalaludin, S. 1990. Ruminomyces elegans gen. et sp. nov. a polycentric anaerobic rumen fungus from cattle. Mycotaxon. 38: 397.

20. Hungate, R. E. 1966. The rumen and its microbes. Academic Press, Inc., New York, USA.

21. Joblin, K. N. 1981. NOTES: Isolation enumeration and maintenance of rumen anaerobic fungi in roll tubes. Appl. Environ. Microbiol. 42:1119.

22. Jones, D. I. H. and Hayward, M. V. 1975. The effect of pepsin pre-treatment of herbage on the pre- 
diction of dry matter digestibility from solubility in fungal cellulase solutions. J. Sci. Food Agric. 26: 711.

23. Lee, S. S., Ha, J. K. and Cheng, K.-J., 2000. Influence of an anaerobic fungal culture administration on in vivo ruminal fermentation and nutrient digestion. Anim. Feed Sci. Technol. 88: 201.

24. Lee, S. S., Moon, Y. H., Kim, C.-H. and Ha, J. K. 2003. In vitro stimulation of rumen microbial fermentation by a rumen anaerobic fungal culture. Anim. Feed Sci. Technol. In press.

25. Li, J., Heath, I. B. and Bauchop, T. 1990. Piromyces mae and Piromyces dumbonica, two new species of monoflagellated anaerobic chytridiomycete fungi from the hindgut of the horse and elephant. Can. J. Bot. 68: 1021.

26. Lowe, S. E., Theodorou, M. K., Trinci, A. P. J. and Hespell, R. B. 1985. Growth of anaerobic rumen fungi on defined and semidefined media lacking rumen fluid. J. Gen. Microbiol. 13:2225.

27. Lowe, S. E., Griffith, G. G., Milne, A., Theodorou, M. K. and Trinci, A. P. J. 1987a. The life cycle and growth kinetics of an anaerobic rumen fungus. J. Gen. Microbiol. 133:1815.

28. Lowe, S. E., Theodorou, M. K. and Trinci, A. P. J. 1987b. Isolation of anaerobic fungi from saliva and feces of sheep. J. Gen. Microbiol. 133:1829.

29. Miller, J. L., Blum, R., Glennon, W. E. and Burton, A. L. 1960. Measurement of carboxymethyl cellulase activity. Anal. Biochem. 1:127.

30. Milne, A., Theodorou, M. K., Jordan, M. G. C., King-Spooner, C. and Trinci, A. P. J. 1989. Survival of anaerobic fungi in faeces, in saliva, and in pure culture. Exp. Mycol. 13:27.

31. Mountfort, D. O. and Asher, R. A. 1989. Production of xylanase by the ruminal anaerobic fungus Neocallimastix frontalis. Appl. Environ. Microbiol. 55: 1016.

32. Orpin, C. G. 1975. Studies on the rumen flagellate Neocallimastix frontalis. J. Gen. Microbiol. 91:249.

33. Orpin, C. G. 1976. Studies on the rumen flagellate Sphaeromonas communis. J. Gen. Microbiol. 94:270.

34. Orpin, C. G. 1977. Invasion of plant tissue in the rumen by the flagellate Neocallimastix frontalis. J. Gen. Microbiol. 98:423.
35. Orpin, C. G. and Joblin, K. N. 1997. The rumen anaerobic fungi. In "The Rumen Microbial Ecosystem" Eds by P. N. Hobson and C. S. Stewart, p. 140. St. Edmundsbury Press, Suffolk, UK.

36. Orpin, C. G. and Munn, E. A. 1986. Neocallimastix patriciarum: new member of the Neocallimsticaccae inhabitating the sheep rumen. Trans. Br. Mycol. Soc. 86: 178.

37. SAS. 1996. User's Guide: Statistics, Version 6 Editions. SAS Inst., Inc., Cary, NC. USA.

38. Teunissen, M. J., Op den Camp, H. J. M., Orpin, C. G., Huis in't Veld, J. H. J. and Vogels, G. D. 1991. Comparison of growth characteristics of anaerobic fungi isolated from ruminant and non-ruminant herbivorous during cultivation in a defined medium. J. Gen. Microbiol. 137:1401.

39. Theodorou, M. K., Gill, M., King-Spooner, C. and Beever, D. E. 1990. Enumeration of anaerobic chytridiomycetes as thallus-forming units: Novel method for quantification of fibrolytic fungal populations from the digestive tract ecosystem. Appl. Environ. Microbiol. 56:1073.

40. Webb, J. and Theodorou, M. K. 1988. A rumen anaerobic fungus of the genus Neocallimastix: Ultrastructure of the polyflagellate zoospore and young thallus. BioSystems. 21:393.

41. Williams, A. G. and Orpin, C. G. 1987. Polysaccharide degrading enzymes formed by three species of rumen fungi grown on a range of carbohydrate substrates. Can. J. Microbiol. 33: 418.

42. Wood, T. M., Wilson, C. A., McCrae, S. I. and Joblin, K. N. 1986. A highly active extracellular cellulase from the anaerobic rumen fungus Neocallimastix frontalis. FEMS Microbiol. Lett. 34:37.

43. 이성실, 하종규, 최윤재. 1995. 반추위 곰팡이의 분리 - 정과 섬유소 분해효소의 특성구명 및 이들의 산업적 이용에 관한 연구. VI. 재래산양 에서 분리된 곰팡이의 동정에 관한 연구. 한영사 지. 19:152.

(접수일자 : 2003. 8. 19. / 채택일자 : 2003. 12. 3.) 